\title{
Fat Tailed Distributions for Deaths in Conflicts and Disasters
}

\author{
Arnab Chatterjee ${ }^{*, *}$ and Bikas K Chakrabarti ${ }^{* \dagger, \S}$ \\ ${ }^{*}$ Condensed Matter Physics Division \\ Saha Institute of Nuclear Physics \\ 1/AF Bidhannagar, Kolkata 700064, India \\ ${ }^{\dagger}$ Economic Research Unit \\ Indian Statistical Institute \\ 203 B. T. Road, Kolkata 700108, India \\ \$arnabchat@gmail.com \\ \$bikask.chakrabarti@saha.ac.in
}

Received 19 January 2017

Accepted 19 January 2017

Published 9 March 2017

\begin{abstract}
We study the statistics of human deaths from wars and similar man-made conflicts as well as natural disasters. The probability distribution of number of people killed in natural disasters as well as man-made situations show power law decay for the largest sizes, with similar exponent values. Comparisons with natural disasters, when event sizes are measured in terms of physical quantities (e.g., energy released in earthquake, volume of rainfall, land area affected in forest fires, etc.) also show striking resemblances. The universal patterns in their statistics suggest that some subtle similarities in their mechanisms and dynamics might be responsible.
\end{abstract}

Keywords: Fat tailed distributions; conflicts; natural disasters; distribution of death; death in natural disasters; war deaths.

\section{Introduction}

Social dynamics is being studied extensively, qualitatively and quantitatively, with the activity increasing at present (See e.g., Refs. 1-5. This is an interdisciplinary research area, which has been a traditional ground for social scientists, but has involved increasing participation of physicists in recent times, apart from mathematicians, computer scientists and others. The behavior of social systems are quite interesting - they demonstrate rich emergent phenomena, including 'stunning regularities', ${ }^{6}$ which result out of interaction of a large number of entities (or agents). ${ }^{7}$ These rich dynamical systems can be studied well using tools of statistical physics. $3,5,53$

I Present address: TCS Research, New Delhi, India.

This is an Open Access article published by World Scientific Publishing Company. It is distributed under the terms of the Creative Commons Attribution 4.0 (CC-BY) License. Further distribution of this work is permitted, provided the original work is properly cited. 
The natural and physical sciences are rich with "laws" and universal patterns. There are not too many in socio-economic systems. The Zipf's law $^{8}$ statistically models the frequency of words uttered in a given natural language, and is also observed to hold for city size, originally reported by Auerbach ${ }^{9}$ and well studied till date. $^{10}$ Zipf law has also been observed for size of firms, income distribution of companies, firm bankruptcy, etc. Formally, the law states give the frequency of the element ranked $k$ (according to size) as $f_{k} \sim 1 / k^{\gamma} \cdot \gamma$ ranges roughly between 0.8 and 1.2 for cities, ${ }^{11}$ around 1 for firm sizes, ${ }^{12} 0.7$ for income of companies ${ }^{13}$ and 0.9 for firm bankruptcy. ${ }^{14}$ The corresponding probability density for the sizes of the elements is given by $P(s) \sim s^{-\nu}(\nu>0)$ and the exponents are related as $\nu=1+\frac{1}{\gamma}$. Hence, the corresponding values of the size exponent $\nu$ are about 1.8-2.2 for city size, 2 for firm sizes, 2.4 for company incomes and 2.1 for firm bankruptcy. This is otherwise known as the Pareto law, as and was first observed for the land wealth of the rich by Pareto, ${ }^{15}$ and subsequently known to hold for income and wealth distributions, with $\nu$ typically between 2 and 3 (see e.g., Ref. 16). The bulk of income distribution follows either an exponential or lognormal distribution (see e.g., Ref. 16). However, consumption expenditure distribution has been mostly reported to have a log-normal bulk with a power law tail. ${ }^{17-20}$ Social networks show certain empirical regularities: e.g., the number of links to websites have a power law tail, ${ }^{21-23}$ degree distribution of movie actor network ${ }^{24}$ and sexual contacts ${ }^{25}$ both show power law tails, co-authorship networks ${ }^{26}$ and citation distributions for articles have power law tails ${ }^{27,28}$ along with a lognormal bulk, ${ }^{29,30}$ among many others.

Several aspects of human lives have been well studied and documented, and certain regularities have already been established. For example, the most studied aspect is that of mortality rate. The Gompertz-Makeham law of mortality describes the age dynamics of human mortality reasonably in the age window 30-80 years, which states that the human death rate is the sum of an age-independent component ${ }^{31}$ and an age-dependent component ${ }^{32}$ which increases exponentially with age.

The history of human civilization has been shaped by events of disasters, wars and conflicts. In recent times, the scale of disaster events have increased remarkably. Growing population around the world has been seen as one of the reasons for the increase in counts of people affected by disaster events, as it has reported that more than 200 million people have been affected by natural disasters every year since $1990,{ }^{33}$ and a much larger number lives at risk of being affected. Similarly, armed conflicts have at times threatened the public health of generations across the globe. ${ }^{34}$ As civilization progressed, armed conflicts and wars have been instrumental in shaping the course of kingdoms and states. Our ancient epics (Mahabharata, Ramayana, Illiad etc.) talk about wars of gigantic scale, and so do ancient historical documents and scriptures. Clashing kingdoms, clans and tribes, these wars lasted from days to years, resulting in fatality of enormous proportions. In the age of kingdoms, wars of different scales, small and large were common. In the recent global political scenario, conflicts happen at a rather smaller scale, except that the two World Wars have seen large scale political polarization and military engagement 
resulting in fatalities of huge proportions. Richardson's early works ${ }^{35,36}$ suggest that the fatality of wars decay as a power law: $P(x) \sim x^{-\alpha}$ for large values of fatality $x$. Subsequent careful analysis have confirmed these findings, e.g., the study of the Correlators of Wars $(\mathrm{CoW})$ database $^{37}$ suggests an exponent $\alpha \simeq 1.4,{ }^{38}$ and this suggests a heavy tailed distribution where the average is controlled by the deadliest of wars. Wars have often been studied in the light of self-organized criticality. ${ }^{39}$ Clauset et al. analyzed the probability distribution of terrorist attack deaths between 1968 and 2005 and found the decay exponent for the power law fit to be around $2.4-2.5,{ }^{40}$ while within shorter spans, the exponent had a large variation, $1.75-2.75$.

Disasters can be broadly classified into natural and man-made, while the natural disasters consist of the majority of recorded calamities. Natural disasters can be further classified into biological, climate-related or geophysical. The earth has seen three times as many natural disasters between 2000 and 2009 compared to that between 1980 and $1989 .{ }^{34}$ What also probably plays a role here is the awareness in recording events, but however, what cannot be ignored is the growth in the climate related events, although the contribution of geophysical events have not changed much. The possible reasons for increase in events can be attributed to deforestation, increased urbanization and rapid industrialization, leading to increase in mean global temperature, massive precipitation and violent storms. A previous study on the total number of people affected and killed at various geographical locations have revealed that its probability distribution has a power law tail with exponent around 1.6-2.1. ${ }^{41}$ Economists have also defined macroeconomic disasters, by studying the real personal consumer expenditure per capita or real GDP per capita, and found their size distribution to have a power law tail with very high exponents, typically around $4 .^{42}$

In this paper, we analyze data for human deaths in man-made conflicts like wars and battles, as well as from disasters. The data sources are given in the following section. The probability distribution of the number of human deaths in a single event is observed to have a broad distribution with a power law tail. We argue that there might be similar mechanisms at play for the two phenomena that result in similar power law exponents.

\section{Results}

We access publicly available databases that keep count of the number of human deaths in wars and conflicts as well as disasters, over a large time span. We use the following datasets:

1. The Battle Deaths Dataset of Peace Research Institute Oslo (PRIO) ${ }^{43}$ for death in conflicts during 1946-2008. Due to uncertainty in the exact number of fatalities, low, high and average estimates are provided for certain events.

2. The war data ${ }^{44}$ from the CoW Project ${ }^{37}$ for deaths during 1816-2007. We use the number of deaths for Intra state, Inter state, Extra state and Non-state wars. 
3. Battle-Related Deaths Dataset from Uppsala Conflict Data Program (UCDP) ${ }^{45}$ for deaths during 1989-2014.

4. Terror attacks data from List of battles and other violent events by death toll from 1910 till July 2016, Wikipedia, ${ }^{46}$

5. The international Disaster Database, $\mathrm{EMDAT}^{47}$ for fatalities from disasters during 1900-2013.

The databases contained information about each single event of war, battle, conflict, terror attack, disaster, with the year of the event, as well as the number of people dead in each event. In some cases, where the numbers are not clearly determined, low, high and possible average estimates are provided (e.g., PRIO data). In Fig. 1, we plot the number of deaths corresponding to different years from the different databases of wars, battles, conflicts and terror attacks. In Fig. 2, we plot the number of deaths corresponding to different years for all disasters, earthquakes, storms and miscellaneous accidents.

We also plot the probability distributions $P(x)$ of events size $x$ measured by the number of deaths in the corresponding event. In Fig. 3(a), we plot the man-made events, like wars, battles, conflicts and terror attacks. For each set, the probability distribution $P(x)$ seems to decay with a power law tail, with an exponents $1.54 \pm$ 0.06 for PRIO, $1.63 \pm 0.03$ for CoW, and $1.64 \pm 0.07$ for UNDP. In Fig. 3(b), we plot the number of people killed in each event of natural disasters like earthquake, storms and miscellaneous accidents. The probability distribution $P(x)$ in these sets also

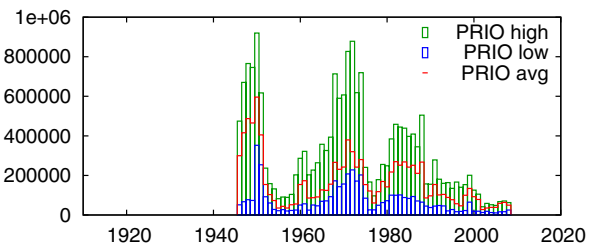

(a)

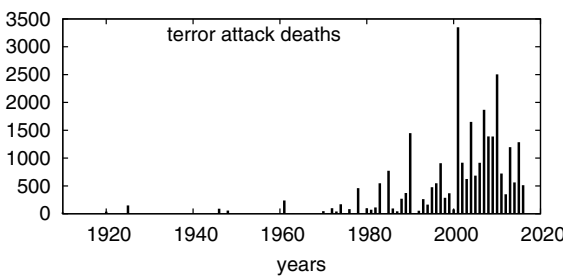

(c)

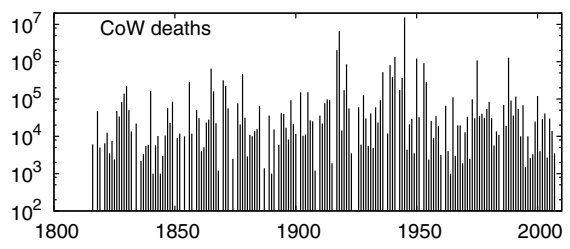

(b)

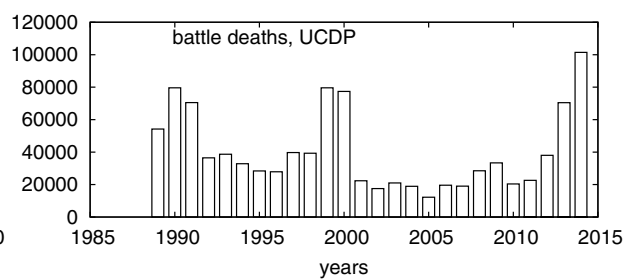

(d)

Fig. 1. Statistics of fatalities over years for wars and conflicts: (a) Number of people died in conflicts during 1946-2008, according to the PRIO database, ${ }^{43}$ with low, high and average estimates; (b) Number of human death according to the CoW database ${ }^{37}$ during 1816-2007, consisting of Intra state, Inter state, Extra state and Non-state wars; (c) Number of human death in terror attack ${ }^{46}$ during 1910 till July 2016; (d) Number of human deaths in battles according to UCDP database ${ }^{45}$ during 1989-2014. 


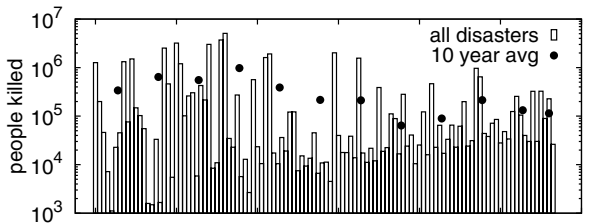

(a)

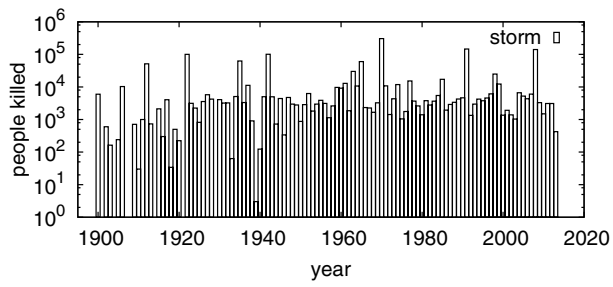

(c)

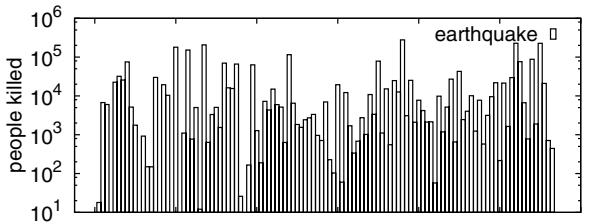

(b)

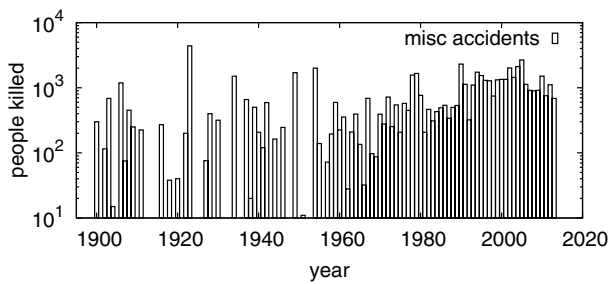

(d)

Fig. 2. Statistics of fatalities over years for disasters during 1900-2013 according to the EMDAT database $^{47}$ : (a) Number of people died due to all disasters, along with 10 years averages indicating a decreasing trend with time. Number of human deaths due to (b) earthquake, (c) storms and (d) miscellaneous accidents in the same period.

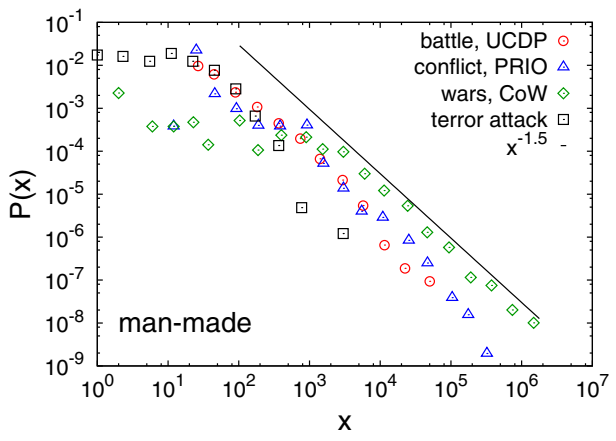

(a)

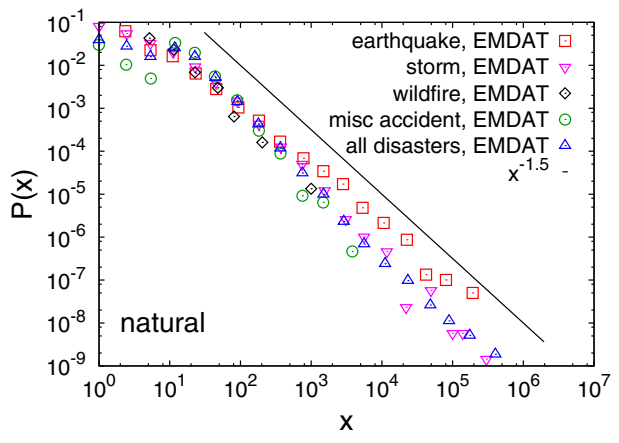

(b)

Fig. 3. The probability distributions $P(x)$ of event size $x$, measured by the number of human deaths in the corresponding event. (a) Man-made events: human deaths from conflicts during 1946-2008, according to the PRIO database ${ }^{43}$ (using lowest estimates), dead according to the CoW database ${ }^{37}$ during 18162007, dead in terror attack ${ }^{46}$ during 1910 till July 2016, and battle deaths according to UCDP database ${ }^{45}$ during 1989-2014. Except the terrorist attack data, all these distributions seem to have a power law tail with similar exponents. The straight line is a guide to the exponent value 1.5 for comparison. (b) Natural disasters: human death from earthquakes, storms, wildfires, miscellaneous accidents, as well as all natural disasters listed in the EMDAT database ${ }^{47}$ during 1900-2013. The precise values of the estimated exponents are given in Table 1. 
Table 1. Dataset description and estimated value of power law exponent $\nu$ as using MLE. ${ }^{48}$

\begin{tabular}{llllcll}
\hline Dataset & Description & Period & Events & Total human death & Range & $\nu$ \\
\hline PRIO $^{43}$ & Conflict & $1946-2008$ & 1957 & $\begin{array}{c}4481398 \\
\text { (lowest estimate) }\end{array}$ & $>1000$ & $1.54 \pm 0.06$ \\
& & & & 40198386 & $>3000$ & $1.63 \pm 0.03$ \\
CoW $^{37}$ & War & $1816-2007$ & 662 & 1049906 & $>1000$ & $1.64 \pm 0.07$ \\
UCDP $^{45}$ & Battle & $1989-2014$ & 1306 & 2564382 & $>1000$ & $1.51 \pm 0.05$ \\
EMDAT earthquake $^{47}$ & Earthquakes & $1900-2013$ & 912 & 1383677 & $>100$ & $1.65 \pm 0.03$ \\
EMDAT storm $^{47}$ & Storms & $1900-2013$ & 2653 & 3665 & $>50$ & $1.51 \pm 0.01$ \\
EMDAT wildfire $^{47}$ & Wildfires & $1900-2013$ & 146 & 62822 & $>100$ & $1.81 \pm 0.12$ \\
EMDAT misc $_{\quad}^{\text {accidents }}{ }^{47}$ & Miscellaneous & $1900-2013$ & 1062 & & & \\
EMDAT all disasters $^{47}$ & all disasters & $1900-2013$ & 16295 & 38463886 & $>5000$ & $1.48 \pm 0.03$ \\
\hline
\end{tabular}

seem to decay with a power law tail, with an exponent close to $1.51 \pm 0.05$, $1.65 \pm 0.03,1.51 \pm 0.01$ and $1.81 \pm 0.12$ respectively for earthquakes, storms, wildfires and miscellaneous accidents. The power law decay exponent for all disaster deaths (these also include mass movements, flood, drought, volcano, industrial reasons, epidemics, extreme temperatures, transport accidents, etc.) is around $1.48 \pm 0.03$. We computed the power law exponents at the tail of the distributions, using the Maximum Likelihood Estimate (MLE) method. ${ }^{48}$ The precise exponent values are given in Table 1.

\section{Summary and Discussions}

In summary, we find that the probability distributions $P(x)$ of event size $x$, measured by the number of human deaths in the corresponding event, goes as $P(x) \sim x^{-\nu}$ for the largest event sizes, with $\nu$ taking values between 1.5 and 1.8 for both man-made conflicts as well as natural disasters. In contrast, in the Guttenberg-Richter law of earthquakes, ${ }^{49}$ the probability of earthquakes releasing energy $E$ goes as $P(E) \sim E^{-\nu}$ with $\nu \simeq 2 .^{50}$ Rainfall has also been reported to show a power law decay with

Table 2. Various socio-economic events and their corresponding size exponent $\nu$ for the power law tail of the event size distribution.

\begin{tabular}{llcc}
\hline Event & Size measured in & $\nu$ & Reference \\
\hline City growth & Population count & $1.8-2.2$ & 11 \\
Firm growth & Number of employees & $\approx 2$ & 12 \\
Income, wealth & Personal income, wealth & $2-3$ & 16 \\
Firm bankruptcy & Debt when firm is bankrupt & $\approx 2.1$ & 14 \\
Earthquake & Energy released & $\approx 2$ & 50 \\
Rainfall & Volume of water & 1.36 & 51 \\
Forest fire & Land area burned & $1.3-1.5$ & 52 \\
Man made events (wars \& conflicts) & Death count & $1.54-1.64$ & this paper, Fig. 3 \\
& & & and Table 1 \\
Natural disasters & Death count & $1.48-1.81$ & this paper, Fig. 3 \\
& & & and Table 1 \\
\hline
\end{tabular}


$\nu \approx 1.36$, measured in terms of volume of rain. ${ }^{51}$ Forest fires, as measured by the area of the land burned down, also shows similar characteristics, with power law decay exponent ranging between 1.3 and 1.5. ${ }^{52}$ Both the man-made conflicts and natural disasters, whether their size or magnitude is measured by released energy (in earthquakes), volume (rain), land area affected (forest fires) or by the fatal consequences given by the number of deaths, the size distribution has a power law tail $P(s) \sim s^{-\nu}$ with $\nu$ values roughly in the range $1.5-1.8$. Table 2 summarizes the estimated values of $\nu$ for different classes of events. The overall similarities suggest that physical modeling efforts may lend sufficient explanation for such statistical behavior of social event size distributions.

\section{Acknowledgments}

A.C. and B.K.C. acknowledge support from B.K.C.'s J. C. Bose Fellowship Research Grant.

\section{References}

1. B. K. Chakrabarti, A. Chakraborti and A. Chatterjee (eds.), Econophysics and Sociophysics: Trends \& Perspectives (Wiley-VCH, Berlin, 2006).

2. D. Stauffer, S. Moss De Oliveira, P. M. C. de Oliveira and J. S. Sá Martins, Biology, Sociology, Geology by Computational Physicists (Elsevier, Amsterdam, 2006).

3. C. Castellano, S. Fortunato and V. Loreto, Statistical physics of social dynamics, Rev. Mod. Phys. 81(2) (2009) 591-646.

4. S. Galam, Sociophysics: A Physicist's Modeling of Psycho-Political Phenomena (Springer, 2012).

5. P. Sen and B. K. Chakrabarti, Sociophysics: An Introduction (Oxford University Press, Oxford, 2013).

6. M. Buchanan, The Social Atom (Marshall Cavendish Business, London, UK, 2007).

7. T. M. Liggett, Stochastic Interacting Systems: Contact, Voter and Exclusion Processes, Vol. 324 (Springer, 1999).

8. G. K. Zipf, Human Behaviour and the Principle of Least-Effort (Addison-Wesley, Cambridge, 1949).

9. F. Auerbach. Das gesetz der bevölkerungskonzentration, Petermanns Geogr. Mitt. 59 (2008) 74-76.

10. X. Gabaix, Zipf's law and the growth of cities, Am. Econ. Rev. 89 (1999) 129-132.

11. X. Gabaix and Y. M. Ioannides, The evolution of city size distributions, Handbook of Regional and Urban Economics, Vol. 4 (2004), pp. 2341-2378.

12. R. L. Axtell, Zipf distribution of us firm sizes, Science 293(5536) (2001) 1818-1820.

13. K. Okuyama, M. Takayasu and H. Takayasu, Zipf's law in income distribution of companies, Physica A 269(1) (1999) 125-131.

14. Y. Fujiwara, Zipf law in firms bankruptcy, Physica A 337(1) (2004) 219-230.

15. V. Pareto, Cours d'economie Politique (Rouge, Lausanne, 1897).

16. B. K. Chakrabarti, A. Chakraborti, S. R. Chakravarty and A. Chatterjee. Econophysics of Income and Wealth Distributions (Cambridge University Press, Cambridge, 2013).

17. T. Mizuno, M. Toriyama, T. Terano and M. Takayasu, Pareto law of the expenditure of a person in convenience stores, Physica A 387(15) (2008) 3931-3935. 
18. G. Fagiolo, L. Alessi, M. Barigozzi and M. Capasso, On the distributional properties of household consumption expenditures: The case of italy, Empir. Econ. 38(3) (2010) 717741.

19. A. Chatterjee, A. S. Chakrabarti, A. Ghosh, A. Chakraborti and T. K. Nandi, Invariant features of spatial inequality in consumption: The case of india, Physica A 442 (2016) $169-181$.

20. A. S. Chakrabarti, A. Chatterjee, T. K. Nandi, A. Ghosh and A. Chakraborti, Quantifying invariant features of within-group inequality in consumption across groups, arXiv:1601.02463, 2016.

21. A. Broder, R. Kumar, F. Maghoul, P. Raghavan, S. Rajagopalan, R. Stata, A. Tomkins and J. Wiener, Graph structure in the web, Comput. Netw. 33(1) (2000) 309-320.

22. R. Albert, H. Jeong and A.-L. Barabási, Error and attack tolerance of complex networks, Nature 406(6794) (2000) 378-382.

23. L. A. Adamic and B. A. Huberman, Power-law distribution of the world wide web, Science, 287(5461) (2000) 2115-2115.

24. A.-L. Barabási and R. Albert, Emergence of scaling in random networks, Science, 286 (5439) (1999) 509-512.

25. F. Liljeros, C. R. Edling, L. A. N. Amaral, H. E. Stanley and Y. Åberg, The web of human sexual contacts, Nature 411(6840) (2001) 907-908.

26. A. L. Barabâsi, H. Jeong, Z. Néda, E. Ravasz, A. Schubert and T. Vicsek, Evolution of the social network of scientific collaborations, Physica A 311(3) (2002) 590-614.

27. W. Shockley, On the statistics of individual variations of productivity in research laboratories, Proc. IRE 45 (1957) 279-290.

28. S. Redner, Citation statistics from 110 years of physical review, Phys. Today $\mathbf{5 8}$ (2005) 49.

29. F. Radicchi, S. Fortunato and C. Castellano, Universality of citation distributions: Toward an objective measure of scientific impact, Proc. Nat. Acad. Sci. 105(45) (2008) $17268-17272$.

30. A. Chatterjee, A. Ghosh and B. K. Chakrabarti, Universality of citation distributions for academic institutions and journals, PloS ONE 11(1) (2016) e0146762.

31. W. M. Makeham, On the law of mortality and the construction of annuity tables, The Assurance Mag. J. Inst. Actuaries 8(6) (1860) 301-310.

32. Be. Gompertz, On the nature of the function expressive of the law of human mortality, and on a new mode of determining the value of life contingencies, Phil. Trans. R. Soc. London, 115 (1825) 513-583.

33. D. Guha-Sapir, F. Vos, R. Below and S. Ponserre, Annual disaster statistical review 2011: The numbers and trends, Technical report, Centre for Research on the Epidemiology of Disasters, UCL (2011).

34. J. Leaning and D. Guha-Sapir, Natural disasters, armed conflict, and public health, New Eng. J. Med. 369(19) (2013) 1836-1842.

35. L. F. Richardson, Variation of the frequency of fatal quarrels with magnitude, J. Am. Stat. Assoc. 43(244) (1948) 523-546.

36. L. F. Richardson, Statistics of Deadly Quarrels (Boxwood Press, Pittsburgh, 1960).

37. The Correlates of War Project: COW War Data, 1816-2007 (v4.0), retreived July (2016), http://www.correlatesofwar.org/data-sets/COW-war.

38. L. E. Cederman, Modeling the size of wars: From billiard balls to sandpiles, Am. Pol. Sci. Rev. 97(1) (2003) 135-150.

39. D. C. Roberts and D. L. Turcotte, Fractality and self-organized criticality of wars, Fractals 6(4) (1998) 351-357. 
40. A. Clauset, M. Young and K. S. Gleditsch, On the frequency of severe terrorist events, $J$. Conflict Resol. 51(1) (2007) 58-87.

41. Ó. Becerra, N. Johnson, P. Meier, J. Restrepo and M. Spagat, Natural disasters, casualties and power laws: A comparative analysis with armed conflict, in Proc. Ann. Meeting Am. Pol. Sc. Assoc. Citeseer (2012).

42. R. J. Barro and T. Jin, On the size distribution of macroeconomic disasters, Econometrica 79(5) (2011) 1567-1589.

43. Peace Research Institute Oslo (PRIO): The Battle Deaths Dataset version 3.0; retreived July (2016). https://www.prio.org/Data/Armed-Conflict/Battle-Deaths/The-BattleDeaths-Dataset-version-30/.

44. M. R. Sarkees and F. W. Wayman, Resort to War: A Data Guide to Inter-State, ExtraState, Intra-State, and Non-State Wars, 1816-2007 (Cq Press, Wiashington DC, 2010).

45. Uppsala Conflict Data Program (UCDP): Battle-Related Deaths Dataset v.5-2015, 19892014; retreived July (2016). http://www.pcr.uu.se/research/ucdp/datasets/ucdp_battlerelated_deaths_dataset/.

46. Wikipedia: List of battles and other violent events by death toll, Terror attacks; retreived July (2016). https://en.wikipedia.org/wiki/List_of_battles_and_other_violent_events_by_ death_toll

47. EM-DAT: The international Disaster Database; retreived July (2014), http://www. emdat.be/database.

48. A. Clauset, C. R. Shalizi and M. E. J. Newman, Power-law distributions in empirical data, SIAM Rev. 51(4) (2009) 661-703.

49. B. Gutenberg and C. F. Richter, Frequency of earthquakes in California, Bull. Seismol. Soc. Am. 34(4) (1944) 185-188.

50. K. Christensen, L. Danon, T. Scanlon and P. Bak, Unified scaling law for earthquakes, Proc. Natl. Acad. Sci. 99(suppl 1) (2002) 2509-2513.

51. O. Peters, C. Hertlein and K. Christensen, A complexity view of rainfall, Phys. Rev. Lett. 88(1) (2001) 018701.

52. B. D. Malamud, G. Morein and D. L. Turcotte, Forest fires: An example of self-organized critical behavior, Science 281(5384) (1998) 1840-1842.

53. Y. Adigüzel, O. Flomenbom and G. U. Coban. From the Physiocrats to Fairness in Nations, Rep. Adv. Phys. Sci. 1750001 (2017). 